\title{
Acute Intermittent Porphyria in Argentina: An Update
}

\author{
Gabriela Nora Cerbino, ${ }^{1}$ Esther Noemí Gerez, ${ }^{1}$ \\ Laura Sabina Varela, ${ }^{1}$ Viviana Alicia Melito, ${ }^{1,2}$ Victoria Estela Parera, ${ }^{1}$ \\ Alcira Batlle, ${ }^{1}$ and María Victoria Rossetti ${ }^{1,2}$ \\ ${ }^{1}$ Centro de Investigaciones sobre Porfirinas y Porfirias (CIPYP), CONICET, Hospital de Clínicas, Universidad de Buenos Aires (UBA), \\ 1120 Buenos Aires, Argentina \\ ${ }^{2}$ Departamento de Química Biológica, Facultad de Ciencias Exactas y Naturales, Universidad de Buenos Aires (UBA), \\ Ciudad Universitaria, Núnez, Universidad de Buenos Aires (UBA), 1120 Buenos Aires, Argentina
}

Correspondence should be addressed to María Victoria Rossetti; rossetti@qb.fcen.uba.ar

Received 9 October 2014; Accepted 20 December 2014

Academic Editor: Hao Deng

Copyright (C) 2015 Gabriela Nora Cerbino et al. This is an open access article distributed under the Creative Commons Attribution License, which permits unrestricted use, distribution, and reproduction in any medium, provided the original work is properly cited.

Porphyrias are a group of metabolic diseases that arise from deficiencies in the heme biosynthetic pathway. A partial deficiency in hydroxymethylbilane synthase (HMBS) produces a hepatic disorder named Acute Intermittent Porphyria (AIP); the acute porphyria is more frequent in Argentina. In this paper we review the results obtained for 101 Argentinean AIP families and 6 AIP families from foreign neighbour countries studied at molecular level at Centro de Investigaciones sobre Porfirinas y Porfirias (CIPYP). Thirty-five different mutations were found, of which 14 were described for the first time in our population. The most prevalent type of mutations was the missense mutations (43\%) followed by splice defects (26\%) and small deletions (20\%). An odd case of a double heterozygous presentation of AIP in a foreign family from Paraguay is discussed. Moreover, it can be noted that 38 new families were found carrying the most frequent mutation in Argentina (p.G111R), increasing to 55.66\% the prevalence of this genetic change in our population and adding further support to our previous hypothesis of a founder effect for this mutation in Argentina. Identification of patients with an overt AIP is important because treatment depends on an accurate diagnosis, but more critical is the identification of asymptomatic relatives to avoid acute attacks which may progress to death.

\section{Introduction}

The porphyrias are a heterogeneous group of metabolic disorders that result from the decreased activity of a specific enzyme of the heme pathway and are characterized by the overproduction and excretion of heme intermediates in urine and/or stool and their accumulation in certain tissues [1-3].

Acute Intermittent Porphyria (AIP, OMIM 176000) is the most common of the acute hepatic porphyrias. It is an autosomal dominant disorder caused by a deficient activity of hydroxymethylbilane synthase (HMBS, EC 4.3.1.8), also referred to as porphobilinogen deaminase, producing a markedly increase in the urinary excretion of ALA and PBG. The symptoms may frequently appear at any time after puberty and are characterized by acute neurovisceral signs which include intermittent attacks of abdominal pain, constipation, vomiting, hypertension, tachycardia, fever, and various peripheral and central nervous system manifestations. Acute attacks may frequently result from exposure to diverse porphyrinogenic drugs, alcohol ingestion, reduced calories intake due to fasting or dieting, infections, and hormones which stimulate heme synthesis by ALA-synthase induction, thereby increasing the production of the porphyrin precursors ALA and PBG $[4,5]$.

HMBS is the third enzyme involved in heme pathway and catalyzes the head to tail condensation of four molecules of PBG to form the lineal tetrapyrrole HMB. It is encoded by a single gene localized at the chromosomal region 1lq23.3. The cDNA and the entire $10 \mathrm{~kb}$ gene have been sequenced including the $5^{\prime}$ regulatory, $3^{\prime}$ regulatory, and intronic regions. The gene contains 15 exons and 2 distinct promoters that generate housekeeping and erythroid transcripts by alternative 
splicing and cDNAs encoding the $44-\mathrm{kD}$ housekeeping and the $42-\mathrm{kD}$ erythroid-specific isoenzymes, which have been isolated and characterized [6].

AIP is the most common acute porphyria in our country [7]. It is an autosomal dominant disorder with incomplete penetrance although some cases of homozygosity or double heterozygosity have been described, in most cases associated with childhood and more severe manifestations [8-21]. The identification of asymptomatic heterozygotes in families with affected individuals is essential for their counselling to avoid specific precipitating factors, but as the enzyme assay is only about $80 \%$ accurate [1], the use of molecular techniques to identify specific mutations in the $H M B S$ gene is essential for accurate diagnosis of affected members in AIP families [7].

To date about 390 different mutations have been identified in the HMBS gene causing AIP (Human Gene Mutation Database HGMD, http://www.hgmd.cf.ac.uk/ac/index.php); most of them were either private or found in a few unrelated families, showing the molecular heterogeneity of AIP.

We review here all the mutations found in 101 Argentinean and 6 foreign AIP families and studied during the last 20 years at CIPYP. Four new mutations and 31 already described genetic changes were found; some of them were detected for the first time in our population. It must be highlighted that 59 unrelated families carry the same mutation, p.G111R (55.66\%), increasing its number with respect to that previously found [22], suggesting a founder effect for this genetic change as has been described for different mutations in other populations [23-25].

\section{Materials and Methods}

2.1. Patients. Informed consent was obtained from all patients following the standards of UNESCO DeclarationsDD.HH Genome and Genetic Data (http://www.unesco.org/ shs/ethics), Declaration of Helsinki was taken into consideration, and the study was approved by the Institutional Research Ethics Committee of the CIPYP, National Scientific and Technical Research Council (CONICET), University of Buenos Aires (UBA).

From March 1994 to July 2014, 106 unrelated Argentinean families were studied at biochemical and molecular level. All patients had current symptoms of AIP and the diagnosis was made on the basis of their clinical history of at least one acute attack associated with increased excretion of ALA and PBG in urine and reduced HMBS activity in red blood cells [1]. The final diagnosis of the patients was established by genetic studies. Unrelatedness was determined by family inquiries.

\subsection{Identification of Mutations}

2.2.1. DNA Isolation and HMBS Amplification. Genomic DNA was extracted from peripheral blood collected in EDTA using the commercial kit illustra ${ }^{\mathrm{TM}}$ blood genomicPrep Mini Spin Kit (GE Healthcare). Mutational analysis was performed amplifying the promoters, all exons, and the intron/exon boundaries of the HMBS gene by PCR using the specific primers shown in Table 1. Promoter regions and genomic sequence from exon 3 to noncoding exon 15 were amplified in only two fragments using Platinum Taq DNA Polymerase High Fidelity enzyme (Invitrogen by Life Technologies). Alternatively, exons 3 to 15 and their flanking intron regions were amplified in 5 fragments as indicated (see Supplementary Material available online at http://dx.doi.org/10.1155/ 2015/946387), employing recombinant Taq DNA Polymerase (Invitrogen by Life Technologies).

2.2.2. RT PCR. RNA was isolated from the leukocytes using the commercial kit Ribo Pure-Blood (Ambion) and reverse transcribed with M-MLV Reverse Transcriptase and Oligo $(\mathrm{dT})_{12-18}$ primers (Invitrogen), according to manufacturer's instructions. The HMBS cDNA was amplified with the primers $\mathrm{Fc}\left(5^{\prime}\right.$ aaagcctgtttaccaaggagc $\left.3^{\prime}\right)-\operatorname{Rc}\left(5^{\prime}\right.$ caccaccagctccaagatgt $3^{\prime}$ ).

All PCR products were checked in $1.5 \%$ agarose gel.

2.2.3. Sequencing Analysis. The amplified products were purified with the Bioneer Accuprep PCR Purification Kit (Bioneer) or QIAquick PCR/Gel Purification Kit (QIAGEN) and were automatically sequenced by Macrogen (Macrogen Inc., Gangseo-gu, Seoul, Korea, ABI3730XL, Macrogen). The sequencing primers are listed in Supplementary Material. All mutations were confirmed by sequencing both DNA strands of at least two different PCR products. To validate the new mutations, their absence in 50 control individuals has been performed. Nucleotides were numbered according to the cDNA sequence for the housekeeping isoform of HMBS transcript variant 1 (GenBank Accession NM_000190.3) in which the A of the ATG initiation codon was numbered as 1.

2.2.4. Databases. The Human Gene Mutation Database (http://www.hgmd.cf.ac.uk/) was used for information about reported mutations in the $H M B S$ gene.

\section{Results}

At present 177 AIP families (299 affected individuals) were diagnosed at CIPYP. Of them, 107 were also studied at molecular level and results for 48 families were already described $[7,28,29,34]$. In the last 10 years 58 new families were also biochemically diagnosed as AIP and molecular analysis revealed 19 mutations, 4 new and 15 already reported of which 7 were described for the first time in our population (Table 1).

From the novel mutations, two were splice site mutations at acceptor splice sites. One was an A to G transition in the penultimate base of intron 8 leading to the in-frame deletion of $15 \mathrm{bp}$ with the loss of the first 5 amino acids of exon 9 (c.423-2A $>\mathrm{G}$ ) by the use of a cryptic site (Figure 1). The other was also an $A$ to $G$ transition in the last base of intron 14 (c.913-1G>A) predicting the skipping of exon 15 .

In another family, an out of frame new duplication of $7 \mathrm{bp}$ in exon 7 which generates a stop codon 17 bp upstream (c. 301_307dupCCCACTG) was found (Figure 2). 


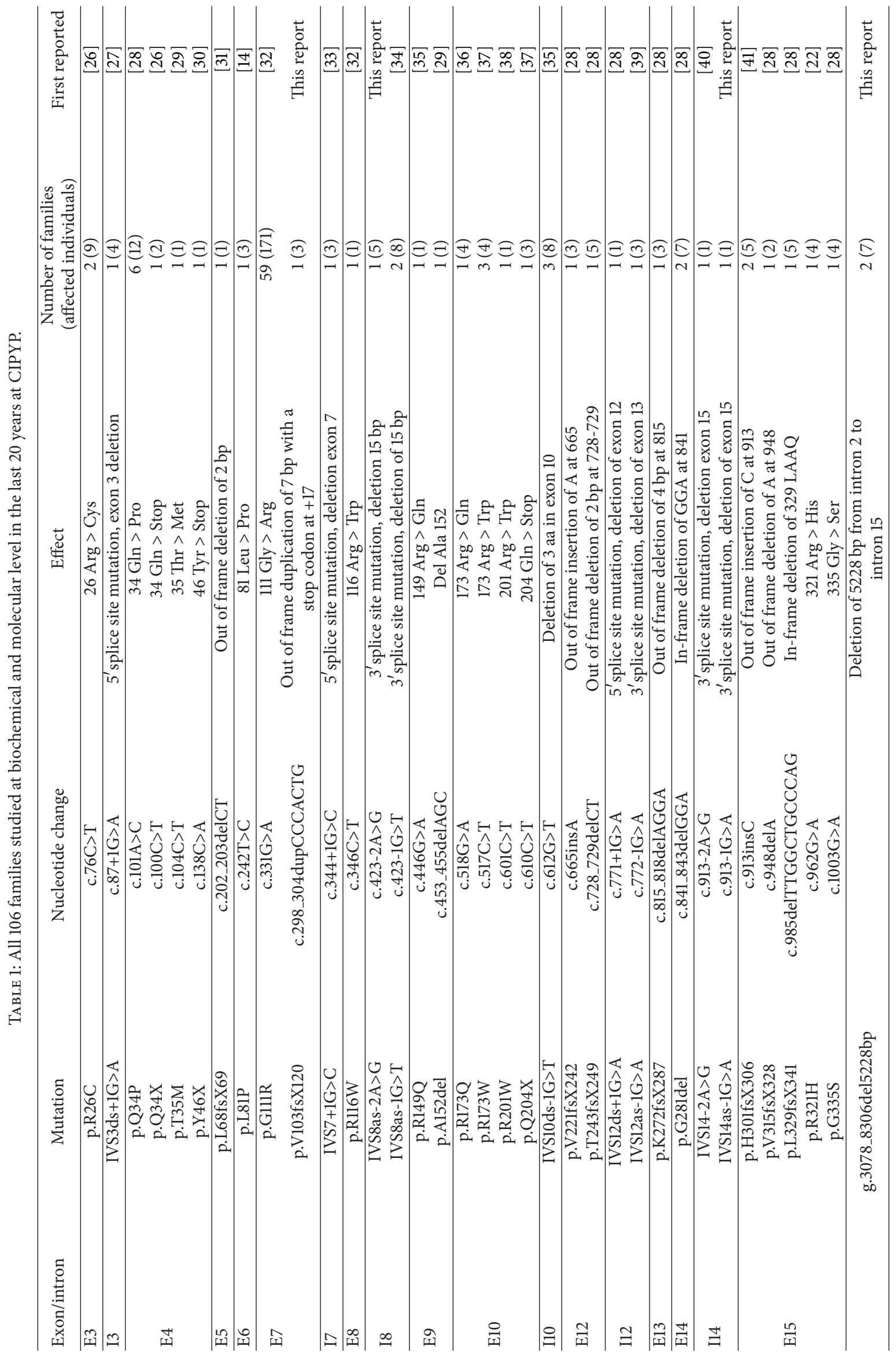


TABle 2: Biochemical data and mutation status of the family from Paraguay.

\begin{tabular}{|c|c|c|c|c|c|c|c|}
\hline Patient & Age & $\begin{array}{c}\text { ALA } \\
\mathrm{mg} / 24 \mathrm{~h}\end{array}$ & $\begin{array}{c}\text { PBG } \\
\mathrm{mg} / 24 \mathrm{~h}\end{array}$ & $\begin{array}{l}\text { Porph. } \\
\mu \mathrm{g} / 24 \mathrm{~h}\end{array}$ & $\begin{array}{l}\text { PPI } \lambda \text { : } \\
619 \mathrm{~nm}\end{array}$ & HMBS activity & Mutation status \\
\hline Proband & 38 & 2.7 & 8.7 & 188 & 1.80 & 44.72 & c.772-1 G>A \\
\hline Mother & 67 & - & - & - & 1.85 & 46.24 & c. $772-1 \mathrm{G}>\mathrm{A}$ \\
\hline Husband & 62 & - & - & - & 1.00 & 61.20 & p.R321H \\
\hline Daughter & 23 & 6.6 & 32.5 & 589 & 1.23 & 58.06 & c. $772-1 \mathrm{G}>\mathrm{A} / \mathrm{p} \cdot \mathrm{R} 321 \mathrm{H}$ \\
\hline Daughter & 26 & 6.1 & 24.7 & 782 & 1.29 & 31.75 & c.772-1 G>A/p.R321H \\
\hline Daughter & 30 & 1.0 & 1.2 & 37 & 1.00 & 44.77 & p.R321H \\
\hline
\end{tabular}

Age in years at diagnosis. Porph.: porphyrins.

Normal values: ALA: $\leq 4 \mathrm{mg} / 24 \mathrm{~h}$ : PBG: $\leq 2 \mathrm{mg} / 24 \mathrm{~h}$; porphyrins: $2-250 \mu \mathrm{g} / 24 \mathrm{~h}$; Plasma Porphyrin Index (PPI) $\leq 1.30$ ( $\lambda: 619) ; \mathrm{HMBS}$ activity: $84.51 \pm 11.96 \mathrm{U} / \mathrm{ml}$ GR (F); $73.13 \pm 13.62 \mathrm{U} / \mathrm{ml}$ GR (M).

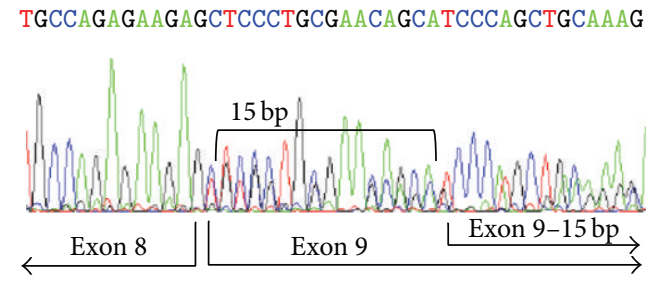

FIGURE 1: Electropherogram showing c.423-2A>G mutation RTPCR product.

In another two families, 2 bands were found when $H M B S$ gene was amplified, one of the expected size and another of $300 \mathrm{bp}$ (Figure 3(a)). The sequencing of the small purified band revealed a large deletion of $5228 \mathrm{bp}$ spanning from intron 2 to noncoding exon 15 (Figures 3(c) and 3(d)).

The other 15 mutations were previously described pointing that 7 of them were identified for the first time in our population (Table 1).

Of note are the results obtained for a foreign family from Paraguay. Two female symptomatic members carried two already described mutations. One was a splice site mutation in the last base of intron 12 inherited from the mother (c.772$1 \mathrm{G}>\mathrm{A}$ ) which leads to exon 13 skipping [39]. The other was a point mutation (c.962G>A) in exon 15 which produces an amino acid change (p.R321H) and was inherited from the father [22]. Another asymptomatic sister carried only this last mutation. The biochemical values and molecular results for this family are shown in Table 2.

In addition, 38 new families carry the p.G111R mutation previously described for another 21 unrelated families [7] ascending the number of unrelated Argentinean families that carry this mutation to 59 (55.66\%) adding further support to our previous hypothesis of a founder effect [28].

\section{Discussion}

During the last 20 years, 35 different mutations were found: 14 described in Argentina for the first time and 21 already reported for other populations. These 35 genetic changes include 15 missense mutations, 9 splice defects, 7 small deletions, 2 small insertions, one gross deletion, and 1duplication.

One of the splice site mutations is located in the -2 position of the acceptor splice site of intron 8 (c.423-2A $>\mathrm{G}$, GENBANK HM856802) leading to the in-frame deletion of $15 \mathrm{bp}$ (Figure 1). The same result has been found for a point mutation in the last base of intron 8 already described for another Argentinean family [34].

The other novel splice site mutation was an A to $G$ transition in the last base of intron 14 (c.913-1G>A). Although no sample was available to carry out RT-PCR studies, as this base is $100 \%$ conserved in the consensus splice site, it is very likely that this substitution leads to exon 15 skipping as it has been described by Puy et al. for a different mutation affecting the same acceptor splice site [39].

The novel frameshift mutation (Figure 2), c.301_307dupCCCACTG (GENBANK HQ7315521), introduces a premature stop codon at exon 8 so the transcript codified by this allele is most likely to be degraded by the nonsense-mediated mRNA decay (NMD) [42]. This mutation has been found in two unrelated Argentinean families (Table 1).

In two families, two bands were found when PCR product was run in an agarose gel, one of the expected size and another of $300 \mathrm{bp}$ (Figure 3(a)). When these were sequenced the large one did not show any genetic change but it showed an apparent homozygosis of the 6 variable SNPs in the studied population (g.3119T $>$ G, g.3581A $>$ G, g.3982T $>$ C, g.6479T $>$ G, g.7064C>A, g.7539C $>$ T) Cerbino [43]. However, as it is shown in Figure 3(b), for two of these SNPs, (g.6479T $>$ G and g.7539C $>$ T), the proband and her sister carry the same allelic variant (6479 G and $7539 \mathrm{C}$ ), but the symptomatic daughter of one of them carries another allelic variant (6479 $\mathrm{T}$ and $7539 \mathrm{~T}$ ) inherited from her father. The analysis of the smaller band indicated that this corresponded to the other allele with a large deletion of $5228 \mathrm{bp}$ spanning from intron 2 to noncoding exon 15. As indicated in Figures 3(c) and 3(d), positions g.3078_g.3081 and g.8306_g.8309 shared the same region (CCCC) so it was impossible to determine the breakpoint of the deletion. Only another gross deletion of $4620 \mathrm{bp}$ but including promoter and exon 1 has been described by Di Pierro et al. [44].

In the family from Paraguay two double heterozygotes relatives were found. The proband of this family has been 
GAAGGACCTGCCCA

TCCTTGAAGGACCTGECCACTGTGCTTCCTCCTGGCT

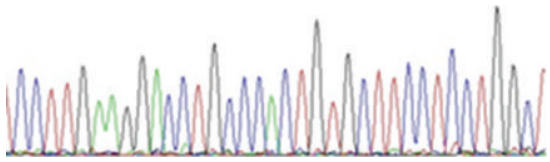

(a)
GAAGGACCTGCCCACTC

TGCTTCCTCCTGGCTTCACCATCGGAGCCATCTGCAAG Control sequence CCCACTGTGCTTCCTCCTGGCTTCACCATCGGAGCCAT Mutated sequence TTGAAGGACCTGCCCACTGTGCTTCCTCCTGGCTTCTGCATCCGAGCCATCAGCCATTTACAATCTTGAAAC

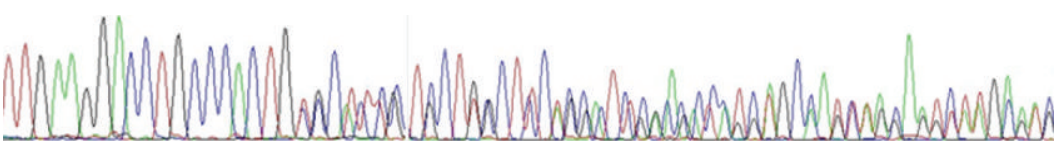

(b)

FIGURE 2: Electropherograms showing (a) control sequence; (b) c.301_307dupCCCACTG mutation; the duplicated sequence is underlined.

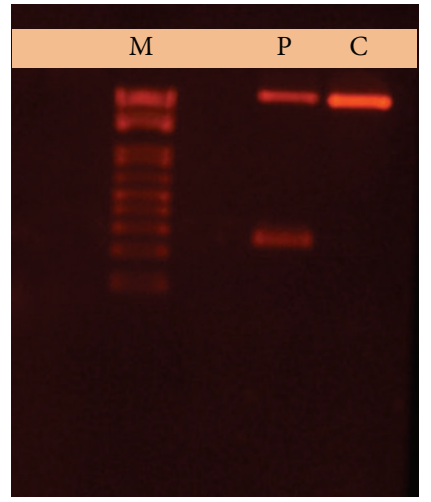

(a)

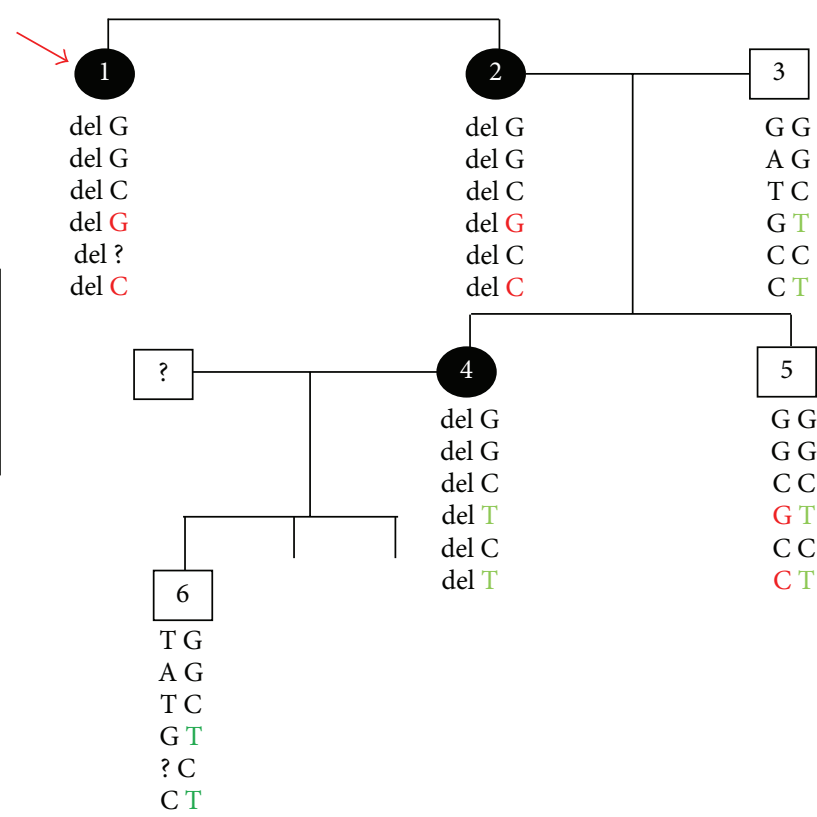

(b)

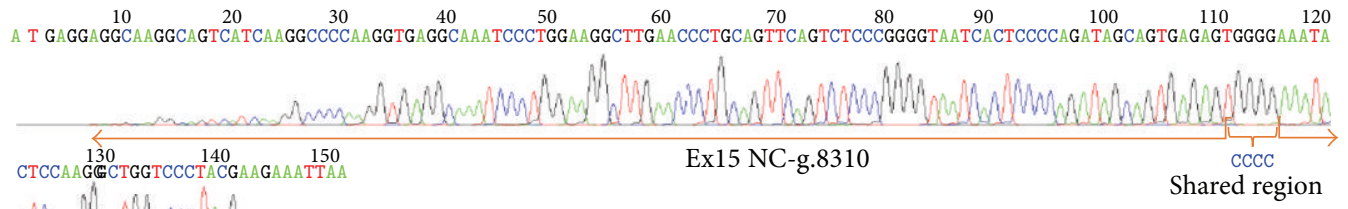

(c)

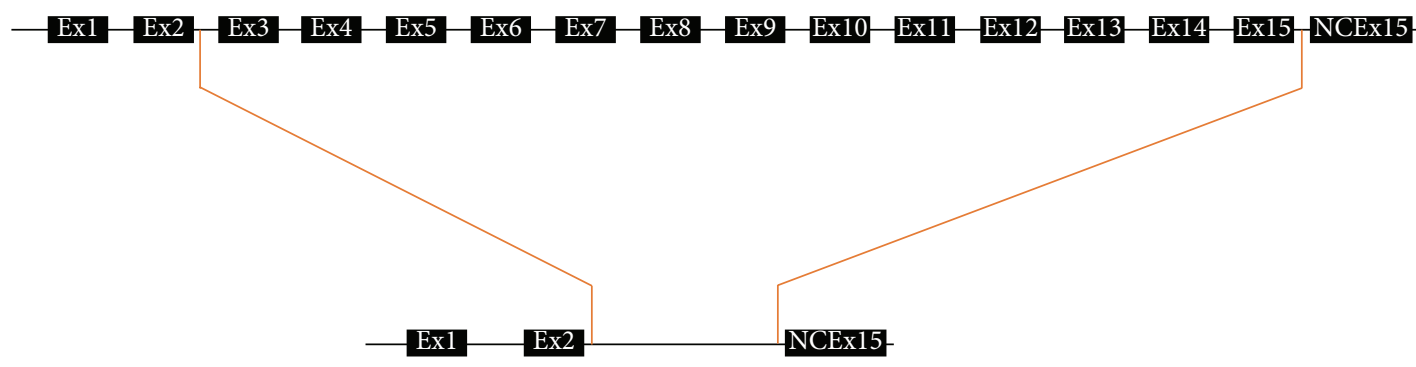

(d)

FIGURE 3: Gross deletion of 5228 bp. (a) PCR product of patient (P), control individual (C), M: 1 kb marker; (b) family SNPs analysis; (c) electropherogram of the $300 \mathrm{bp}$ band showing the shared region between intron 2 and noncodifying exon 15; (d) scheme showing the deleted region. 
diagnosed as AIP 15 years ago carrying one reported mutation, c.772-1G>A, a splice site mutation which leads to exon 13 skipping [39]. When three of her daughters came for diagnosis, it was found that one of them, asymptomatic but with a HMBS activity reduced to $50 \%$ of control value, did not carry the family mutation. A reexamination of mother DNA confirmed only the previous mutation but a more extensive study of her daughters indicated that two of them carry two mutations, the maternal mutation and another previously described missense mutation, p.R321H [22], inherited from their father. The asymptomatic daughter carries this last genetic change. It is interesting to note that these patients developed the symptomatology recently (23 and 26 years old) and only one of them occasionally suffered from some abdominal pain. In most of homozygous or double heterozygous AIP reported cases the enzyme activity was severely reduced and the symptomatology was developed at an early age with severe neurological manifestations [13, 15, 16, 18-21]. In several of these cases essential arginine residues for enzyme activity are affected [45-47]. In these new cases the mutations found do not seem to be essential for enzyme expression or activity. This is likely true for the missense mutation which affects a nonconserved arginine residue in exon 15 located in the 29-residue insert between strands $\beta 3$ and $\alpha 2$ in the domain 3 only present in the human enzyme sequence [47]. However, the splice site mutation leads to exon 13 skipping [39], an exon where the residue Cys $^{261}$ is located to which the essential DPM (dipyrromethane) cofactor is bound [47]. Nevertheless this combined heterozygous genotype does not seem to have a more serious impact on HMBS activity than in the heterozygous form, since the activity of the three sisters is approximately the same. These results highlighted the importance of carrying out a complete genotype investigation of family members of a known carrier.

Finally 38 new families carrying the frequent p.G111R mutation have been characterized leading to 59 (55.66\%) the number of Argentinean families carrying this genetic change. The other mutations were found in one or in a few families. Efforts were made to know if the AIP patients showing this mutation have a common ancestral origin. Detailed pedigrees were unavailable, because either relatives of many of the patients were dead or the relatives themselves had limited knowledge of their families ancestry. Since the p.G111R mutation occurs at a hot spot CpG dinucleotide, it can be possible that the mutation had been originated several times independently. However, a preliminary analysis of four intragenic and four flanking DNA polymorphic markers indicated that all tested patients with p.G111R mutation $(7 / 21)$ had at least one common allele for all intragenic and flanking markers. Argentinean AIP patients with other mutations had different alleles for the markers [28]. These previous results had suggested that individuals carrying this mutation were most likely related. Extended haplotype analysis on a large group of families with the p.G111R mutation and their relatives add further evidence to our previous hypothesis about a founder effect for this mutation in the Argentinean population [43]. Microsatellite studies in these families are being carried out.

\section{Conclusions}

This study emphasizes the molecular heterogeneity of AIP and the importance of molecular techniques as the most appropriate tools for detecting and identifying specific mutations in carriers of affected families to avoid the contact with precipitating agents.

\section{Conflict of Interests}

The authors declare that there is no conflict of interests regarding the publication of this paper.

\section{Acknowledgments}

Gabriela Nora Cerbino is a postgraduate student from the University of Buenos Aires. Alcira Batlle, María Victoria Rossetti, Victoria Estela Parera, and Esther Noemí Gerez are Superior, Independent, and Associated Researchers from CONICET. Viviana Alicia Melito and Laura Sabina Varela are Principal and Associated Members at the Technical Career from CONICET. The authors would like to thank H. Muramatsu, MD, Dr. MN Guolo, Lic. LM Oliveri, and Mrs. VI Castillo for their technical assistance. This work was supported by Grants X253 (2004-2007), X304 (2004-2007), EX195 (2008-2010), EX165 (2008-2010), and W542 (20112014) from UBA, PICT 0268 (2009-2012) from ANPCYT, and PIP 049 (2012-2014) from CONICET.

\section{References}

[1] A. M. C. Batlle, "Porfirias y Porfirinas. Aspectos clínicos, bioquímicos y biología molecular," Acta Bioquímica Clínica Latinoamericana. Serie: Actualizaciones Médico-Bioquímicas, supplement 3, pp. 145-171, 1997.

[2] A. Pietrangelo, “Theporphyrias: pathophysiology," Internal and Emergency Medicine, supplement 1, pp. S65-S71, 2010.

[3] H. Puy, L. Gouya, and J.-C. Deybach, "Porphyrias," The Lancet, vol. 375, no. 9718, pp. 924-937, 2010.

[4] K. E. Anderson, S. Sassa, D. F. Bishop, and R. J. Desnick, "Disorders of heme biosynthesis: X-linked sideroblasticanemia and the porphyrias," in The Metabolic and Molecular Basis of Inherited Disease, C. R. Scriver, A. L. Beaudet, D. Valle, and W. S. Sly, Eds., vol. 2, pp. 2991-3062, McGraw-Hill, New York, NY, USA, 2001.

[5] R. Kauppinen, “Porphyrias," The Lancet, vol. 365, no. 9455, pp. 241-252, 2005.

[6] R. J. Desnick, M. Balwani, and K. E. Anderson, "Inherited Porphyrias," in Emery and Rimoin's Principles and Practice of Medical Genetics, D. L. Rimoin, R. E. Pyeritz, and B. Korf, Eds., chapter 99, pp. 1-32, Elsevier, San Diego, Calif, USA, 6th edition, 2013.

[7] V. E. Parera, A. de Siervi, L. Varela, M. V. Rossetti, and A. M. D. C. Batlle, "Acute porphyrias in the Argentinean population: a review," Cellular and Molecular Biology, vol. 49, no. 4, pp. 493500, 2003.

[8] C. Picat, M. H. Delfau, F. W. M. de Rooij et al., "Identification of the mutations in the parents of a patient with a putative compound heterozygosity for acute intermittent porphyria," 
Journal of Inherited Metabolic Disease, vol. 13, no. 5, pp. 684$686,1990$.

[9] G. J. J. Beukeveld, B. G. Wolthers, Y. Nordmann, J. C. Deybach, B. Grandchamp, and S. K. Wadman, "A retrospective study of a patient with homozygous form of acute intermittent porphyria," Journal of Inherited Metabolic Disease, vol. 13, no. 5, pp. 673-683, 1990.

[10] D. H. Llewellyn, S. J. Smyth, G. H. Elder, A. C. Hutchesson, J. M. Rattenbury, and M. F. Smith, "Homozygous acute intermittent porphyria: compound heterozygosity for adjacent base transitions in the same codon of the porphobilinogen deaminase gene," Human Genetics, vol. 89, no. 1, pp. 97-98, 1992.

[11] R. J. Hift, P. N. Meissner, G. Todd et al., "Homozygous variegate porphyria: an evolving clinical syndrome," Postgraduate Medical Journal, vol. 69, no. 816, pp. 781-786, 1993.

[12] A. Edixhoven-Bosdijk, F. W. de Rooij, E. de Baar-Heesakkers, and J. H. Wilson, "Residual activity of human porphobilinogen deaminase with R167Q or R167W mutations: an explanation for survival of homozygous and compound heterozygous acute intermittent porphyrics," Cellular and Molecular Biology, vol. 48, no. 8, pp. 861-866, 2002.

[13] C. Solis, A. Martinez-Bermejo, T. P. Naidich et al., "Acute intermittent porphyria: studies of the severe homozygous dominant disease provides insights into the neurologic attacks in acute porphyrias," Archives of Neurology, vol. 61, no. 11, pp. 1764-1770, 2004.

[14] J. Hessels, G. Voortman, A. van der Wagen, C. van der Elzen, H. Scheffer, and F. M. J. Zuijderhoudt, "Homozygous acute intermittent porphyria in a 7-years-old boy with massive excretions of porphyrins and porphyrin precursors," Journal of Inherited Metabolic Disease, vol. 27, no. 1, pp. 19-27, 2004.

[15] L. Sheppard and T. Dorman, "Anesthesia in a child with homozygous porphobilinogen deaminase deficiency: a severe form of acute intermittent porphyria," Paediatric Anaesthesia, vol. 15, no. 5, pp. 426-428, 2005.

[16] E. McGovern, P. Fleming, and A. O'Marcaigh, "The dental management of five paediatric patients with a history of acute intermittent porphyria," European Archives of Paediatric Dentistry, vol. 8, no. 4, pp. 215-218, 2007.

[17] V. A. Melito, M. V. Rossetti, V. E. Parera, and A. Batlle, "Porfirias poco frecuentes. Casos detectados en la población argentina," Revista Argentina de Dermatología, vol. 87, pp. 248-263, 2006.

[18] A. Dibi, H. Aitouamar, and A. Bentahila, "Recurrent flaccid paralysis indicative of acute intermittent porphyria in a child," Archives de Pédiatrie, vol. 17, no. 12, pp. 1670-1672, 2010.

[19] J. I. Bhat, U. A. Qureeshi, and M. A. Bhat, "Acute intermittent porphyria with transient cortical blindness," Indian Pediatrics, vol. 47, no. 11, pp. 977-978, 2010.

[20] E. Anyaegbu, M. Goodman, S.-Y. Ahn, M. Thangarajh, M. Wong, and M. Shinawi, "Acute intermittent porphyria: a diagnostic challenge," Journal of Child Neurology, vol. 27, no. 7, pp. 917-921, 2012.

[21] B. Zhao, Q. Wei, Y. Wang, Y. Chen, and H. Shang, "Posterior reversible encephalopathy syndrome in acute intermittent porphyria," Pediatric Neurology, vol. 51, no. 3, pp. 457-460, 2014.

[22] M. M. Schuurmans, X. Schneider-Yin, U. B. Rüfenacht et al., "Influence of age and gender on the clinical expression of acute intermittent porphyria based on molecular study of porphobilinogen deaminase gene among Swiss patient," Molecular Medicine, vol. 7, no. 8, pp. 535-542, 2001.

[23] J.-S. Lee and M. Anvret, "Identification of the most common mutation within the porphobilinogen deaminase gene in
Swedish patients with acute intermittent porphyria," Proceedings of the National Academy of Sciences of the United States of America, vol. 88, no. 23, pp. 10912-10915, 1991.

[24] X.-F. Gu, F. de Rooij, J. S. Lee et al., "High prevalence of a point mutation in the porphobilinogen deaminase gene in Dutch patients with acute intermittent porphyria," Human Genetics, vol. 91, no. 2, pp. 128-130, 1993.

[25] X. Schneider-Yin, M. Hergersberg, D. E. Goldgar et al., "Ancestral founder of mutation W283X in the porphobilinogen deaminase gene among acute intermittent porphyria patients," Human Heredity, vol. 54, no. 2, pp. 69-81, 2002.

[26] R. Kauppinen, S. Mustajoki, H. Pihlaja, L. Peltonen, and P. Mustajoki, "Acute intermittent porphyria in Finland: 19 mutations in the porphobilinogen deaminase gene," Human Molecular Genetics, vol. 4, no. 2, pp. 215-222, 1995.

[27] G. Lundin, J. Hashemi, Y. Floderus et al., "Four mutations in the porphobilinogen deaminase gene in patients with acute intermittent porphyria," Journal of Medical Genetics, vol. 32, no. 12, pp. 979-981, 1995.

[28] A. de Siervi, M. V. Rossetti, V. E. Parera et al., "Identification and characterization of hydroxymethylbilane synthase mutations causing acute intermittent porphyria: evidence for an ancestral founder of the common G111R mutation," American Journal of Medical Genetics, vol. 86, no. 4, pp. 366-375, 1999.

[29] A. de Siervi, D. E. W. Cádiz, V. E. Parera, A. M. D. C. Batlle, and M. V. Rossetti, "Identification and characterization of two novel mutations that produce acute intermittent porphyria: a 3-base deletion (841-843delGGA) and a missense mutation (T35M)," Human Mutation, vol. 16, no. 4, p. 373, 2000.

[30] A. Gregor, X. Schneider-Yin, U. Szlendak et al., "Molecular study of the hydroxymethylbilane synthase gene (HMBS) among Polish patients with acute intermittent porphyria," Human Mutation, vol. 19, no. 3, p. 310, 2002.

[31] Y. A. Luchinina, V. L. Surin, A. V. Luk'yanenko, I. V. Karpova, Y. S. Pustovoit, and S. K. Kravchenko, "Molecular diagnostics of acute intermittent porphyria in Russia," European Journal of Human Genetics, vol.13, supplement 1, p. 134, 2005, Proceedings of the European Society of Human Genetics International Conference.

[32] X.-F. Gu, F. de Rooij, E. de Baar et al., "Two novel mutations of the porphobilinogen deaminase gene in acute intermittent porphyria," Human Molecular Genetics, vol. 2, no. 10, pp. 17351736, 1993.

[33] M. D. Cappellini, F. M. di Montemuros, E. di Pierro, and G. Fiorelli, "Hematologically important mutations: acute intermittent porphyria," Blood Cells, Molecules, and Diseases, vol. 28, no. 1, pp. 5-12, 2002.

[34] A. de Siervi, M. Méndez, V. E. Parera, L. Varela, A. M. Batlle, and M. V. Rossetti, "Acute intermittent porphyria: characterization of two novel mutations in the porphobilinogen deaminase gene, one amino acid deletion (453-455delAGC) and one splicing aceptor site mutation (IVS8-1G>T)," Human Mutation, vol. 14, no. 4 , article 355, 1999.

[35] M. H. Delfau, C. Picat, F. de Rooij et al., "Molecular heterogeneity of acute intermittent porphyria: identification of four additional mutations resulting in the CRIM-negative subtype of the disease," The American Journal of Human Genetics, vol. 49, no. 2, pp. 421-428, 1991.

[36] M. H. Delfau, C. Picat, F. W. M. de Rooij et al., "Two different point $\mathrm{G}$ to A mutations in exon 10 of the porphobilinogen deaminase gene are responsible for acute intermittent porphyria," The Journal of Clinical Investigation, vol. 86, no. 5, pp. 1511-1516, 1990. 
[37] C. S. Mgone, W. G. Lanyon, M. R. Moore, G. V. Louie, and J. M. Connor, "Identification of five novel mutations in the porphobilinogen deaminase gene," Human Molecular Genetics, vol. 3, no. 5, pp. 809-811, 1994.

[38] C.-H. Chen, K. H. Astrin, G. Lee, K. E. Anderson, and R. J. Desnick, "Acute intermittent porphyria: identification and expression of exonic mutations in the hydroxymethylbilane synthase gene. An initiation codon missense mutation in the housekeeping transcript causes "variant acute intermittent porphyria" with normal expression of the erythroid-specific enzyme," The Journal of Clinical Investigation, vol. 94, no. 5, pp. 1927-1937, 1994.

[39] H. Puy, J. C. Deybach, J. Lamoril et al., "Molecular epidemiology and diagnosis of PBG deaminase gene defects in acute intermittent porphyria," The American Journal of Human Genetics, vol. 60, no. 6, pp. 1373-1383, 1997.

[40] Y. Floderus, P. M. Shoolingin-Jordan, and P. Harper, "Acute intermittent porphyria in Sweden. Molecular, functional and clinical consequences of some new mutations found in the porphobilinogen deaminase gene," Clinical Genetics, vol. 62, no. 4, pp. 288-297, 2002.

[41] H. Puy, J. C. Deybach, J. Lamoril, A. M. Robreau, and Y. Nordmann, "Detection of four novel mutations in the porphobilinogen deaminase gene in French Caucasian patients with acute intermittent porphyria," Human Heredity, vol. 46, no. 3, pp. 177-180, 1996.

[42] L. E. Maquat, "Nonsense-mediated mRNA decay: splicing, translation and mRNP dynamics," Nature Reviews Molecular Cell Biology, vol. 5, no. 2, pp. 89-99, 2004.

[43] G. N. Cerbino, High prevalence of p.G111R mutation in Argentine patients with acute intermittent Porphyria. New mutations found in PBGD gene [Pre Graduate thesis], 2011.

[44] E. Di Pierro, V. Brancaleoni, F. Stanzial, F. Benedicenti, C. Castellan, and M. D. Cappellini, "Novel human pathological mutations. Gene symbol: HMBS. Disease: porphyria, acute intermittent," Human Genetics, vol. 126, no. 2, p. 339, 2009.

[45] P. D. Brownlie, R. Lambert, G. V. Louie et al., "The threedimensional structures of mutants of porphobilinogen deaminase: toward an understanding of the structural basis of acute intermittent porphyria," Protein Science, vol. 3, no. 10, pp. 16441650, 1994.

[46] G. Song, Y. Li, C. Cheng et al., "Structural insight into acute intermittent porphyria," The FASEB Journal, vol. 23, no. 2, pp. 396-404, 2009.

[47] R. Gill, S. E. Kolstoe, F. Mohammed et al., "Structure of human porphobilinogen deaminase at $2.8 \AA$ : the molecular basis of acute intermittent porphyria," Biochemical Journal, vol. 420, no. 1, pp. 17-25, 2009. 

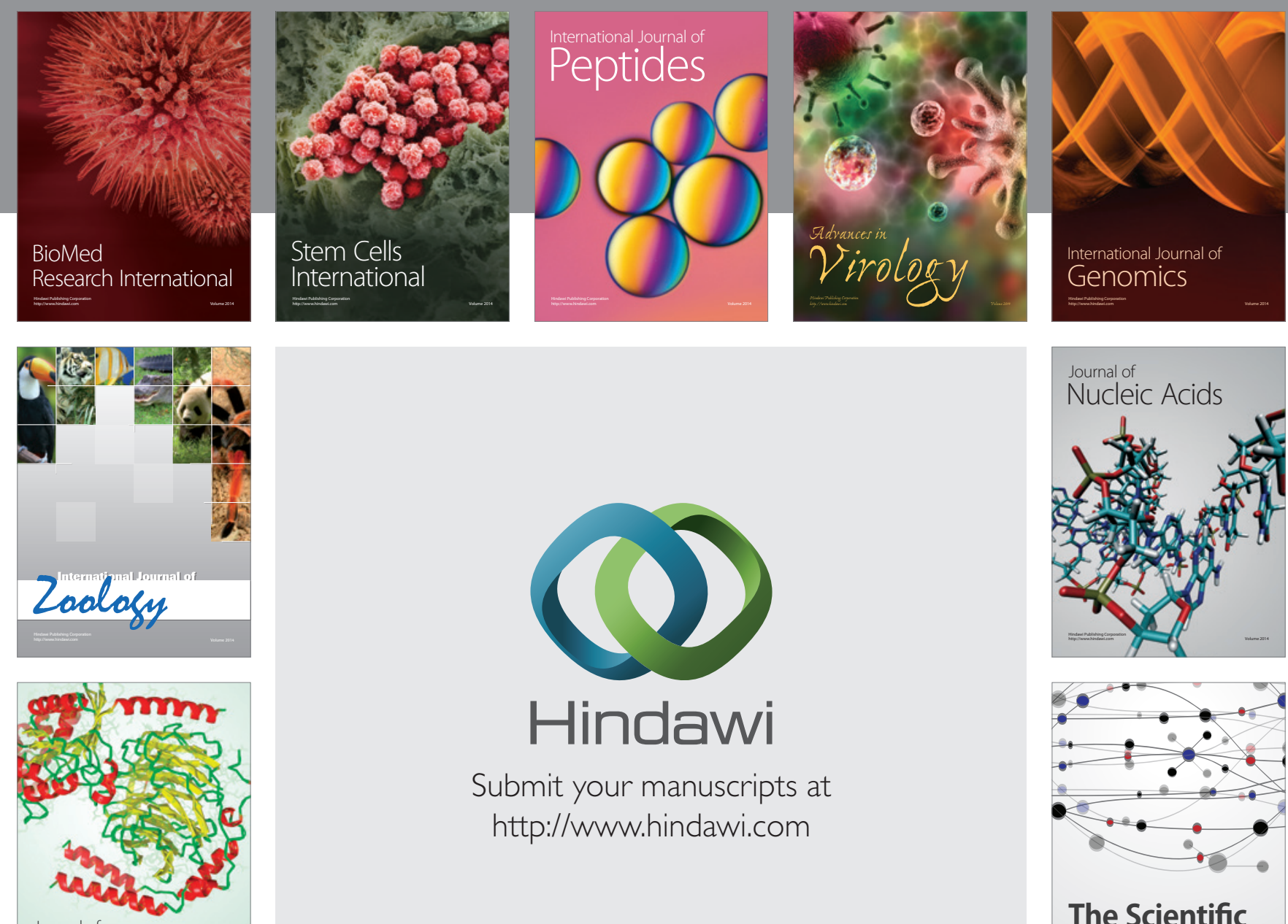

Submit your manuscripts at

http://www.hindawi.com

Journal of
Signal Transduction
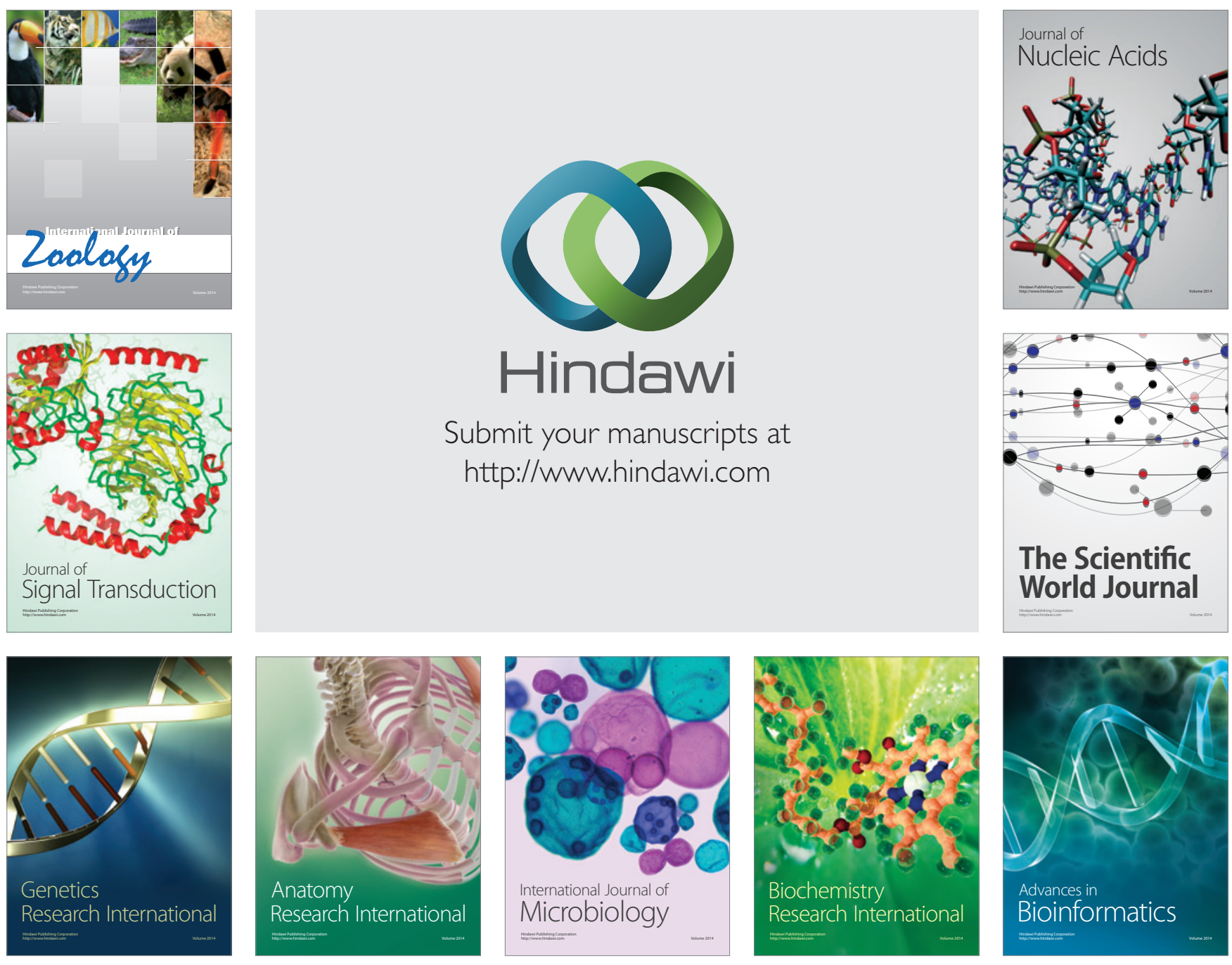

The Scientific World Journal
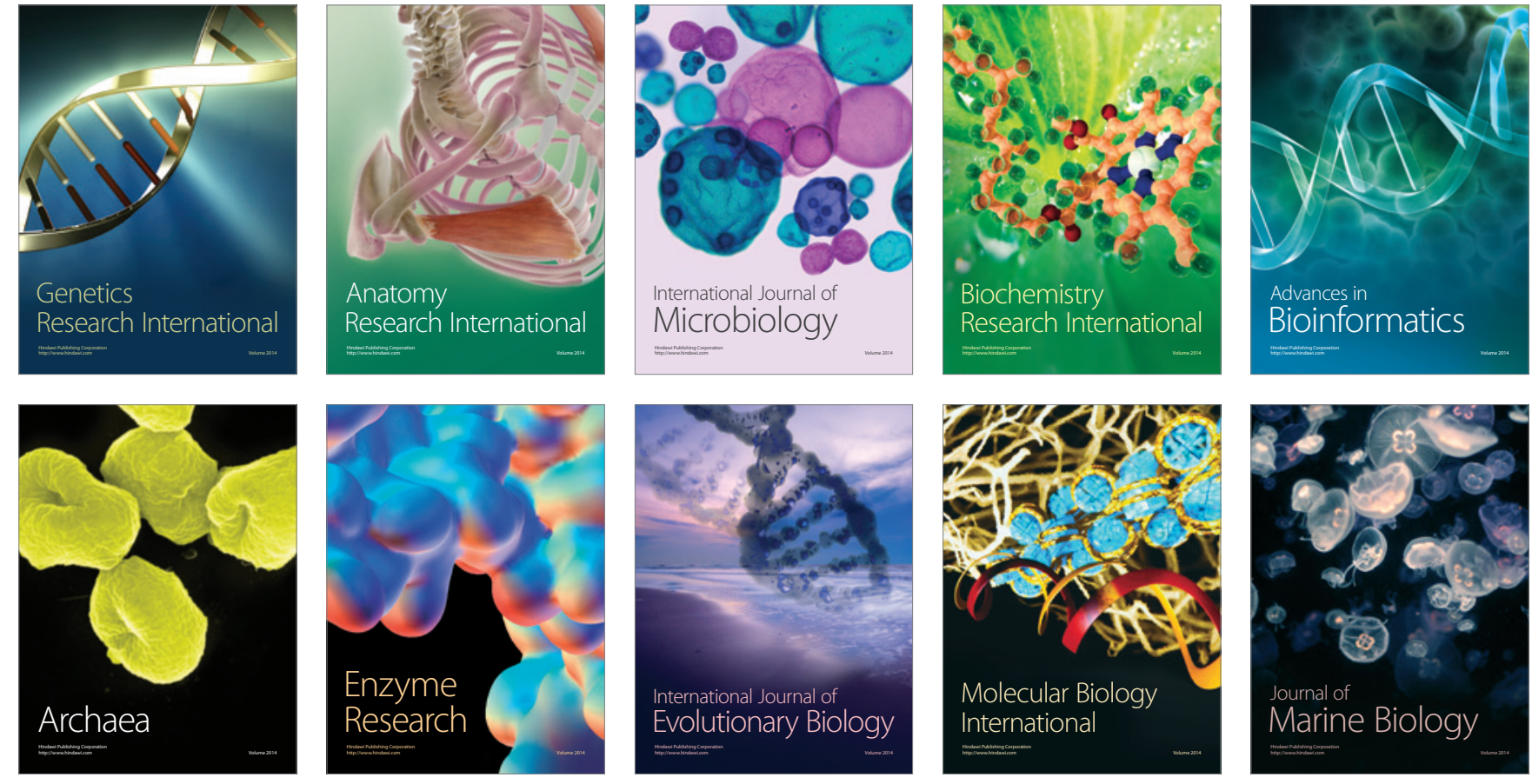